\title{
Circular shunt in bidirectional cavopulmonary anastomosis
}

\author{
K. M. Krishnamoorthy, DM, DNB, FACC, and S. S. Sivasankaran, DM, DNB
}

From the Sree Chitra Tirunal Institute of Medical Sciences and Technology, Trivandrum, India. Disclosures: Authors have nothing to disclose with regard to commercial support.

Received for publication March 9, 2016; revisions received April 12, 2016; accepted for publication April 15, 2016; available ahead of print May 14, 2016.

Address for reprints: K. M. Krishnamoorthy, DM, DNB, FACC, Cardiology, Sree Chitra Tirunal Institute of Med-

ical Sciences and Technology, Trivandrum, India 695011 (E-mail: kmkm@sctimst.ac.in).

J Thorac Cardiovasc Surg 2016;152:921-3

$0022-5223 / \$ 36.00$

Copyright (C) 2016 by The American Association for Thoracic Surgery

http://dx.doi.org/10.1016/j.jtcvs.2016.04.067

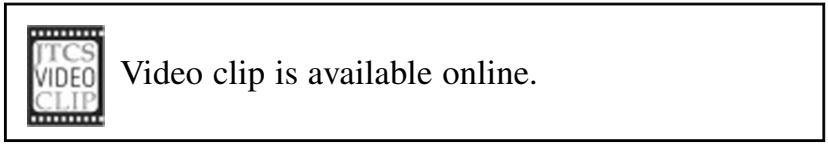

A right cavopulmonary shunt was done for an infant with tricuspid atresia, ventricular defect, and pulmonary stenosis, improving his oxygen saturation from $83 \%$ to $90 \%$. At 6 years of age, the patient had worsening cyanosis with a saturation of $65 \%$. Echocardiography showed a

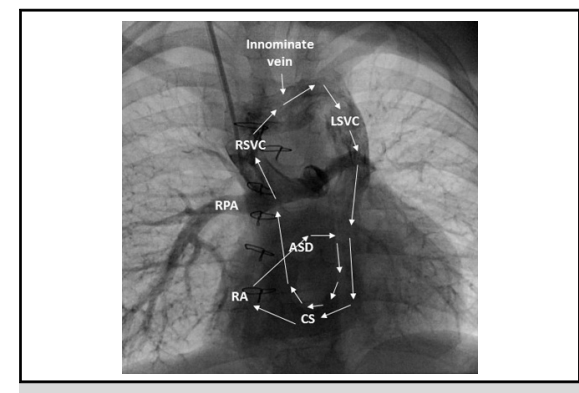

Circular shunt after cavopulmonary connection.

\section{Central Message}

A venovenous collateral involving left superior vena cava developed after a cavopulmonary connection in the presence of antegrade pulmonary flow. Circular shunt and ineffective circulation resulted.

See Editorial Commentary page 923.
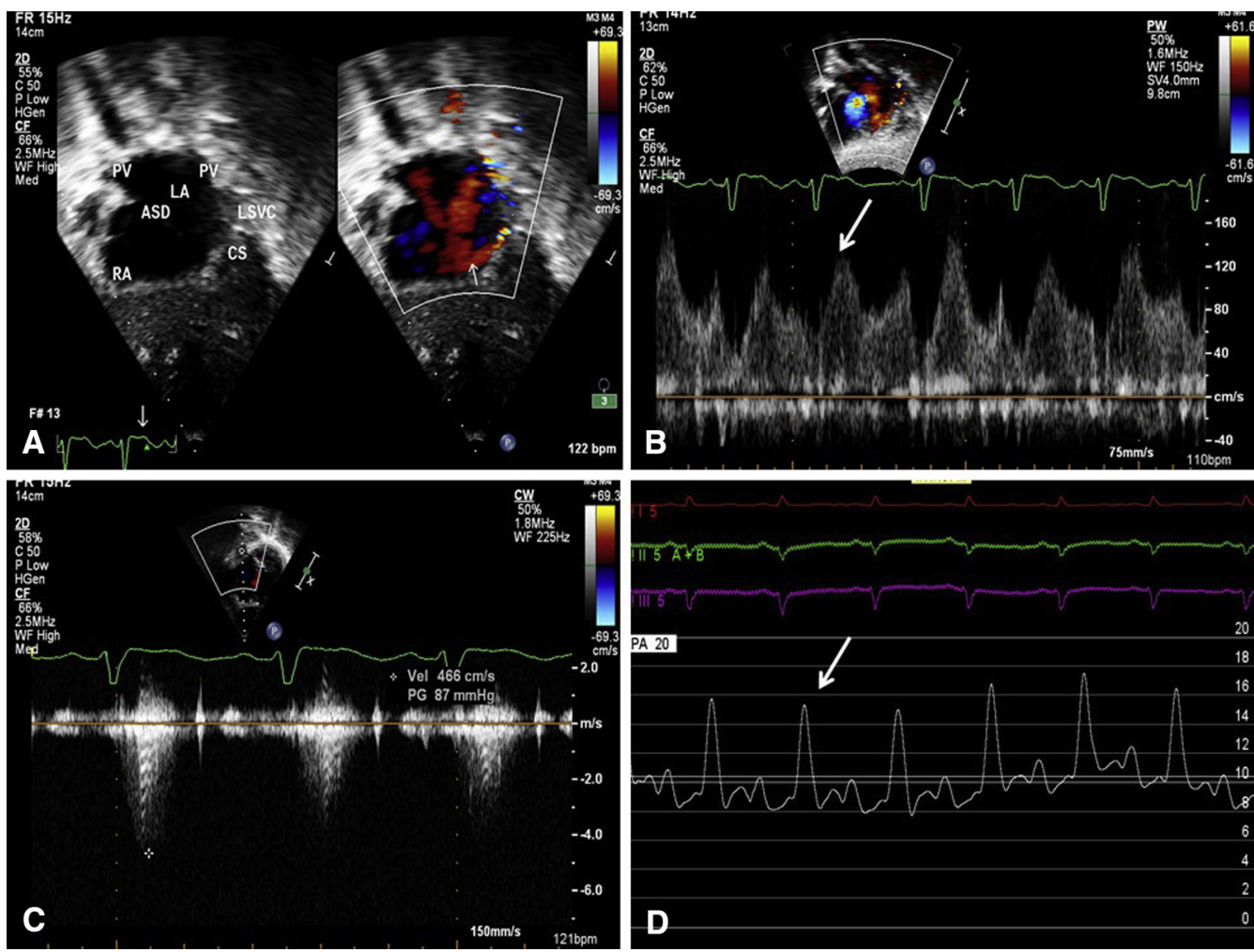

FIGURE 1. Echocardiographic views. A, Subcostal 4-chamber view echocardiography showing dilated left vena cava (LSVC), coronary sinus (CS), and atrial septal defect $(A S D)$. PV, Right and left upper pulmonary veins; $L A$, left atrium; RA, right atrium. White arrow points to entry of the coronary sinus into the right atrium. B, Pulsed-wave Doppler image showing systolic wave in the coronary sinus (white arrow) corresponding to antegrade flow in pulmonary artery (see panel D). C, Continuous-wave Doppler image showing a gradient across the pulmonary valve. D, Pulmonary arterial $(P A)$ pressure tracing during catheterization. White arrow points to systolic antegrade flow. 


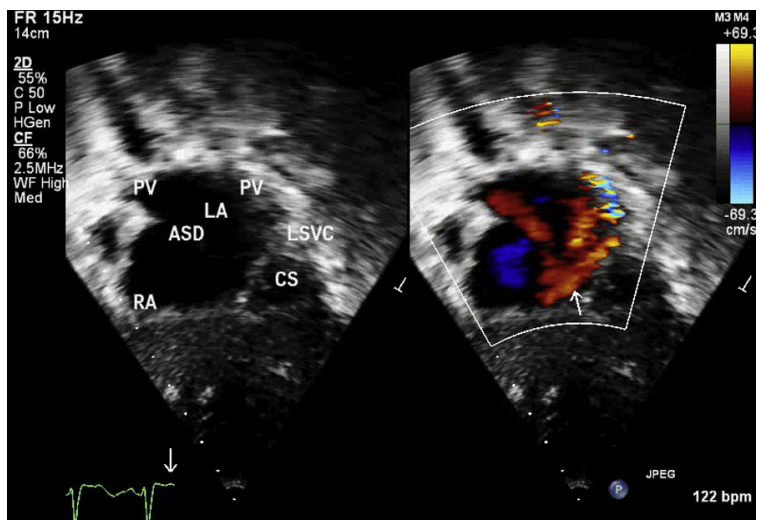

VIDEO 1. Subcostal 4-chamber echocardiographic view showing dilated coronary sinus and left superior vena cava. White arrow points to the entry of the coronary sinus, which shows pulsatile flow. $P V$, Right and left upper pulmonary veins; $L A$, left atrium; $A S D$, atrial septal defect; $L S V C$, left superior vena cava; $C S$, coronary sinus; $R A$, right atrium. Video available at http://www.jtcvsonline.org.

dilated coronary sinus with pulsatile flow into the right atrium (Figure 1, $A$ and $B$, and Video 1 ). The pulmonary stenosis gradient was greater than $87 \mathrm{~mm} \mathrm{Hg}$ (Figure 1,C). The cavopulmonary anastomosis decompressed the pulmonary artery to the right atrium through the innominate vein, left superior vena cava, and coronary sinus (angiography shown in Figure 2, A, and Video 2). Systolic pulsation in the cavopulmonary circuit confirmed antegrade pulmonary flow with a mean pressure of $12 \mathrm{~mm} \mathrm{Hg}$ (Figure 1, D). Taking part in the circuit, the left superior vena cava and coronary sinus were dilated.

Circular shunts are intracardiac communications where the shunted blood returns to the same chamber without

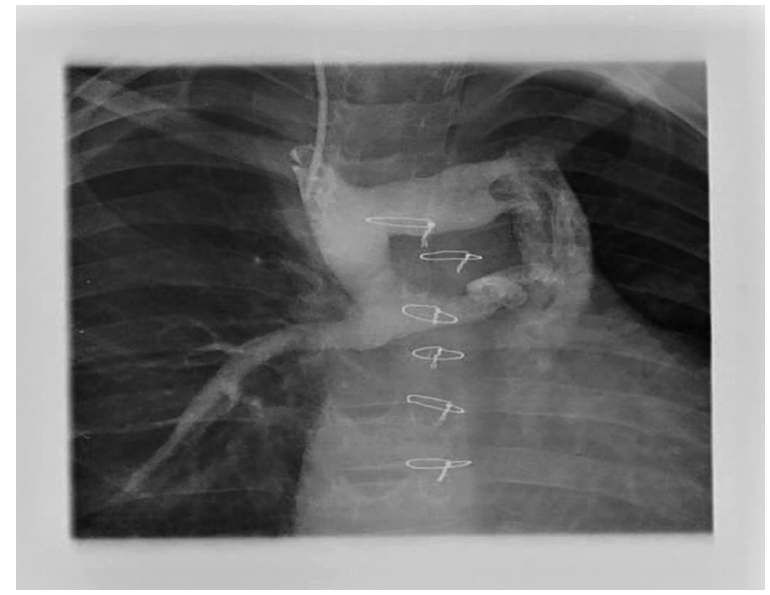

VIDEO 2. Cineangiographic view of the circular shunt. Video available at http://www.jtcvsonline.org.

traversing a capillary bed. ${ }^{1}$ Systemic venovenous collaterals open up after a cavopulmonary anastomosis, causing desaturation. ${ }^{2}$ Recanalization of the left superior vena cava may be seen on follow-up. ${ }^{3}$ These channels can be closed percutaneously or surgically to improve the hemodynamics and saturation. When such connections occur in the setting of antegrade pulmonary flow, however, as seen in our patient, a circular shunt will develop (Figure 2,B), with wasted cardiac output and worsening cyanosis. Bilateral cavopulmonary connection is planned for our patient. Careful inspection and ligation of a remnant of the left superior vena cava, even in the presence of a sizeable bridging innominate vein, could avoid this late complication.
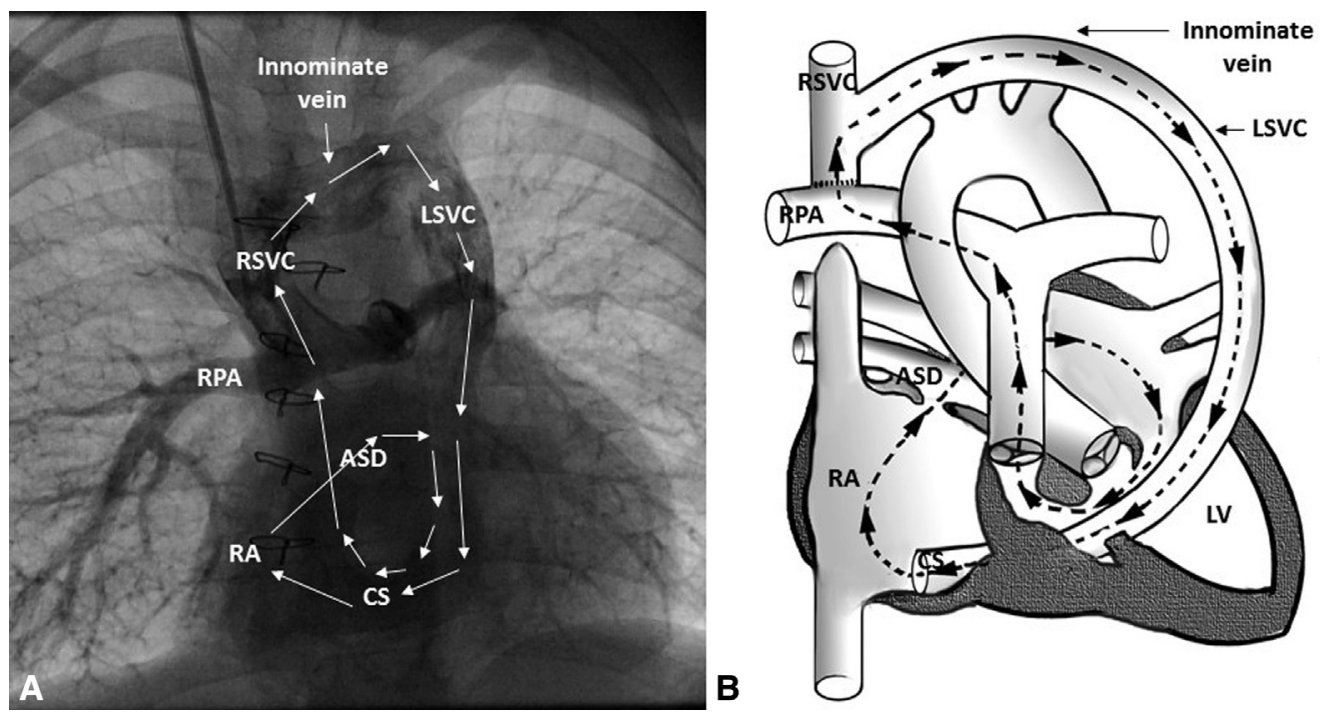

FIGURE 2. Angiographic view. A, Frozen frame of angiographic view of the circular shunt. B, Schematic view of the circular shunt. RSVC, Right superior vena cava; $L S V C$, left superior vena cava; $R P A$, right pulmonary artery; $A S D$, atrial septal defect; $R A$, right atrium; $C S$, coronary sinus; $L V$, left ventricle. 


\section{References}

1. Shone JD, Anderson RC, Elliott LP, Amplatz K, Lillehei CW, Edwards JE. "Circular" shunt resulting from coexistent ventricular septal defect, pulmonary valvular stenosis, congenital tricuspid insufficiency, and patent foramen ovale. Am Heart J. 1962;64:547-55.
2. Magee AG, McCrindle BW, Mawson J, Benson LN, Williams WG, Freedom RM Systemic venous collateral development after the bidirectional cavopulmonary anastomosis. Prevalence and predictors. J Am Coll Cardiol. 1998;32:502-8.

3. Girish G, Agarwal S, Datt V, Tomar AS, Satsangi DK. Unexplained desaturation following a Glenn shunt. Ann Card Anaesth. 2014;17:74-5.

\section{EDITORIAL COMMENTARY}

\section{A vicious circle}

\section{Christoph Haller, MD}

From the Division of Cardiovascular Surgery, Hospital for Sick Children and University of Toronto, Toronto, Ontario, Canada.

Disclosures: Author has nothing to disclose with regard to commercial support.

Received for publication May 4, 2016; accepted for publication May 6, 2016; available ahead of print June 18, 2016.

Address for reprints: Christoph Haller, MD, Division of Cardiovascular Surgery, Hospital for Sick Children and University of Toronto, 555 University Ave, Toronto, Ontario, Canada M5G 1X8 (E-mail: christoph.haller@ sickkids.ca).

J Thorac Cardiovasc Surg 2016;152:923-4

$0022-5223 / \$ 36.00$

Copyright (C) 2016 by The American Association for Thoracic Surgery

http://dx.doi.org/10.1016/j.jtcvs.2016.05.034

Venovenous collaterals are commonly encountered after bidirectional cavopulmonary shunt (BCPS) or Fontan procedures. Up to one-third of patients after BCPS procedures have been diagnosed with collateral channels, more than half of them draining below the diaphragm. ${ }^{1}$

Krishnamoorthy and colleagues ${ }^{2}$ report a very unique scenario in a patient with tricuspid atresia, ventricular septal defect, and pulmonary stenosis. After uneventful BCPS, the patient developed cyanosis caused by a decompressing left superior vena cava (LSVC) draining to the coronary sinus. This resulted in a circular shunt from the pulmonary artery via BCPS, innominate vein, and LSVC to the atria and ventricles back into the pulmonary artery.

Recanalization of an occluded LSVC has been reported after BCPS and Fontan procedures. ${ }^{3-5}$ Girisch and colleagues $^{5}$ reported on 2 patients with double inlet left ventricle and pulmonary stenosis who experienced cyanosis after Fontan due to a recanalized LSVC. ${ }^{5}$ A patient with unbalanced atrioventricular septal defect, hypoplasia of the right ventricle, and ventricular septal defect showed desaturation caused by reopening of an LSVC pathway. ${ }^{6}$ Nevertheless, recirculation was never mentioned despite the persistent connection of the right ventricle to the pulmonary arteries. A case series at our institution described a patient with tricuspid atresia, ventricular septal defect, and recanalized LSVC that resulted in a circular shunt across an initially ligated pulmonary artery after Fontan completion. ${ }^{3}$

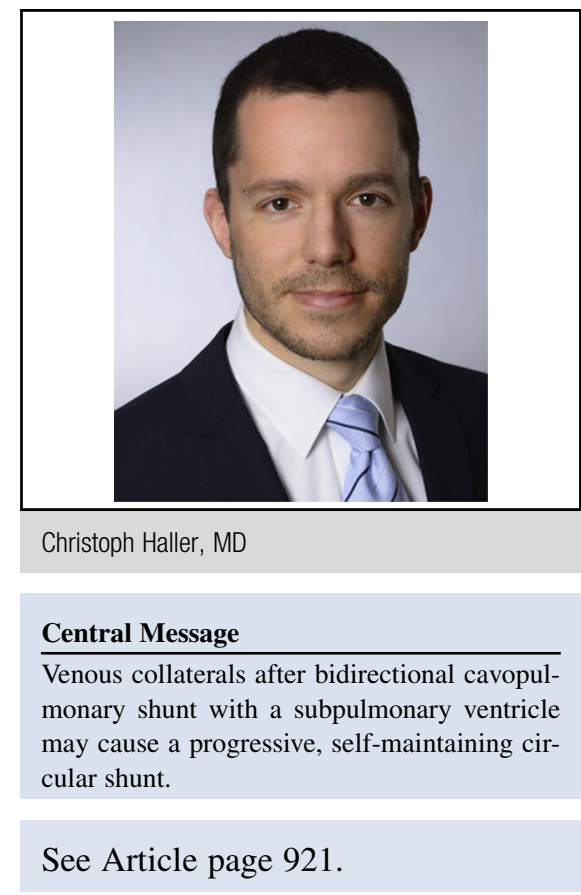

Although the LSVC in the presented patient can be seen as one of many possible collateral channels, the physiology is quite unique. Opposed to the solely decompressing effect of a systemic venous collateral after BCPS without right ventricle to pulmonary artery connection, the reopening of the LSVC in the setting of a subpulmonary ventricle initiates a vicious circle. The pulmonary blood flow caused by the subpulmonary ventricle leads to higher pressure in the BCPS. ${ }^{7,8}$ This in turn increases the pressure difference between the upper and lower venous compartment and the decompressing blood flow through the LSVC. The increased direct return to the atrium not only reduces the transpulmonary gradient, but also increases ventricular preload and right ventricular stroke volume, thereby further reducing the driving force for antegrade BCPS flow. 